\title{
QUANTITATIVE BACTERIOLOGY OF THE VAGINAL FLORA IN GENITAL DISEASE
}

\author{
M. Wilks, R. N. Thin* and SoAd TabaQchali $\dagger$ \\ Departments of Medical Microbiology and ${ }^{*}$ Genital Medicine, St Bartholomew's \\ Hospital, West Smithfield, London EC1A $7 B E$
}

\begin{abstract}
SummaRY. Samples from the posterior vaginal fornix of 102 women with various clinical conditions were analysed by a quantitative method. Aerobes were isolated from all but one of the specimens at a mean concentration of $7 \cdot 2 \log _{10} \mathrm{cfu} / \mathrm{g}$ and anaerobes from 92 specimens at a mean concentration of $8 \cdot 1 \log _{10} \mathrm{cfu} / \mathrm{g}$. In most clinical conditions and in a control group of asymptomatic women, anaerobes outnumbered aerobes by about ten to one (one $\log _{10}$ unit). The most common organisms were aerobic and anaerobic lactobacilli, coryneforms, Staphylococcus epidermidis, Bacteroides spp. and anaerobic gram-positive cocci. Lactobacilli did not appear to confer any protective effect by excluding the presence of other organisms such as Gardnerella vaginalis or anaerobes. The isolation of anaerobic organisms from the vagina cannot be regarded as being of pathogenic significance without other supporting evidence.
\end{abstract}

\section{INTRODUCTION}

Alterations of the vaginal bacterial flora have long been associated with cases of vaginitis not attributable to Trichomonas vaginalis, Candida albicans or uterine infection (Curtis, 1913). The presence of anaerobic bacteria in the genital tract of most women has been known since the 1920s (Harris and Brown, 1929; Weinstein, 1938). In spite of these early observations most studies have used qualitative methods, often to detect only aerobic and facultatively anaerobic organisms (Galask, Larsen and Ohm, 1976).

In contrast, quantitative studies of the flora of the gastro-intestinal tract have not only established an agreed concept of normal flora but have also shown how changes in that flora relate to intestinal disorders (Tabaqchali, 1970). These advances have been made possible by the introduction of improved bacteriological techniques for the isolation of anaerobic organisms (Hungate, 1950; Holdeman, Cato and Moore, 1977) and by the development of reliable quantitative sampling techniques (Clarke, 1977). During the last few years several groups of workers (Levison et al., 1977; Onderdonk et al., 1977; Lindner, Plantema and Hoogkamp-Korstanje, 1978) have used quantitative sampling techniques to collect a defined volume or weight of vaginal secretion for

Received 6 Oct. 1983; accepted 13 Feb. 1984.

† Requests for reprints should be sent to Dr S. Tabaqchali. 
analysis by improved anaerobic methods. We recently reported our evaluation of these techniques (Wilks, Thin and Tabaqchali, 1982) and described a method that we devised for quantitative studies.

In this paper we report the quantitative bacteriology of the vaginal flora in several different clinical conditions and in association with various pathogens to determine whether changes in the normal vaginal flora are involved in the pathogenesis of genital disease.

\section{PATIENTS AND METHODS}

Patients. Samples were collected from 102 patients attending the Department of Genital Medicine at St Bartholomew's Hospital for the detection of conventional pathogens such as gonococci, candida and trichomonads, and also for quantitative analysis of the aerobic and anaerobic bacterial flora by the method that we described previously (Wilks et al., 1982).

Patients were grouped according to their disease syndromes and the pathogens isolated, i.e., gonococcal disease (GC), Trichomonas vaginalis (TV), candida, non-specific vaginitis (NSV), non-specific genital infection (NSGI), non-specific urethritis contacts (NSU contacts) and a control group (non VD). Patients from whom two or more pathogens were isolated, e.g., N. gonorrhoeae and T. vaginalis, were omitted from this report.

In this study, NSV was defined as the presence of an abnormal amount of vaginal discharge, without specifying colour, with or without inflammation of the vaginal mucosa (as judged by a single clinician), in the absence of other pathogens and of any contact with known sexually transmitted disease. In addition, these patients did not have a gross excess of leukocytes in the gram-stained cervical smear, nor did they have inflammatory changes affecting the epithelial cells on the Papanicolaou-stained cervical smears. NSGI was defined as the presence of a gross excess of leukocytes, inflammatory changes affecting epithelial cells, the absence of GC, TV or candida and the absence of contact with a patient with any sexually transmitted disease. Patients in the control group had no excess of vaginal discharge, no GC, TV or candida, none of the inflammatory changes noted in patients with NSGI and no known contact with any sexually transmitted disease. Women who had taken antimicrobials in the preceding month were excluded. Patient's age, stage of menstrual cycle, contraceptive practice and parity were also recorded.

Sampling. Samples were collected through a speculum from the posterior vaginal fornix with a conventional bacteriological loop and placed into a preweighed tube of modified prereduced Cary Blair medium (Wilks et al., 1982).

Processing of specimens. After reweighing, the tube was passed into an anaerobic chamber where the specimen was homogenised and then serially diluted. For anaerobic incubation samples $(100 \mu \mathrm{l})$ were spread on the surface of the following media which had been poured in the chamber: Brucella blood agar, neomycin $(100 \mu \mathrm{g} / \mathrm{ml})$-blood agar and kanamycin $(50 \mu \mathrm{g} / \mathrm{ml})-$ vancomycin $(5 \mu \mathrm{g} / \mathrm{ml})$-lysed blood agar were prepared according to the methods of Sutter, Vargo and Finegold (1975) except that horse blood $(10 \% \mathrm{v} / \mathrm{v})$ was substituted for sheep blood $(5 \% \mathrm{v} / \mathrm{v})$; Rogosa agar (Difco) with a final $p \mathrm{H}$ of 5.4 as a selective medium for lactobacilli. The dilution tubes were then removed from the chamber and $100-\mu 1$ samples were spread on plates of the following media for aerobic cultivation: Blood agar (Tissue Culture Services, 10 Henry Road, Slough, Berks SL1 2QI), MacConkey agar (Oxoid) and modified Thayer-Martin medium (Riddell and Buck, 1970). All anaerobic culture plates were incubated in the chamber for up to 7 days at $35^{\circ} \mathrm{C}$ and the aerobic plates were incubated for 2 or 3 days at $35^{\circ} \mathrm{C}$ in an atmosphere of air $+\mathrm{CO}_{2} 5 \%$.

Enumeration and identification of organisms. Different colony types were counted and subcultured on to fresh media for identification. Counts were expressed as the logarithm of the number of colony-forming units per gram $\left(\log _{10} \mathrm{cfu} / \mathrm{g}\right)$. Anaerobic isolates were identified by the methods listed in the Anaerobe Laboratory Manual (Holdeman et al., 1977). Prereduced anaerobically sterilised media (Scott Laboratories, Fiskerville, Rhode Island, USA) were used for biochemical tests. Metabolic end products were detected by gas-liquid chromatography using a Perkin Elmer Sigma 10 chromatograph (Perkin Elmer, Post Office Lane, Beaconsfield, 
Bucks HP9 1QA). Aerobes were identified primarily by the methods of Cowan (1974) with the following exceptions: organisms identified as $G$. vaginalis were catalase negative, non haemolytic on horse blood agar but weakly $\beta$-haemolytic on human blood agar, sensitive to metronidazole (50- $\mu \mathrm{g}$ disk) and nitrofurantoin (150- $\mu \mathrm{g}$ disk) and hydrolysed hippurate (Piot et al., 1982); 'aerobic coryneforms' were organisms that fitted the mini definition of the genus Corynebacterium given by Cowan (1974) but cannot now be assumed to be members of the genus Corynebacterium sensu stricto (Collins and Jones, 1981).

\section{RESULTS}

The results of the bacterial counts in the different conditions are summarised in table I. Aerobic bacteria were isolated from all the specimens except one and anaerobes were found in most specimens. The overall mean count was $8 \cdot 2 \log _{10} \mathrm{cfu} / \mathrm{g}$. Anaerobes typically outnumbered aerobes by about tenfold (one log unit) except in patients from the GC and NSU contact groups. Means of $2 \cdot 1$ aerobic and $2 \cdot 3$ anaerobic species per specimen were isolated.

Aerobic flora. The aerobic organisms found (tables II and III) were predominantly gram-positive organisms, mainly lactobacilli, coryneforms and $S$. epidermidis. These occurred widely in all the clinical groups. G. vaginalis occurred much less frequently and was not uniformly distributed. It was much more common in patients with NSV (eight out of 14) and in NSU-contact patients (six out of 16) than in other groups. $S$. epidermidis was much more common than $S$. aureus. In contrast, the gram-negative aerobic flora was much more scanty in distribution and in concentration of organisms. $E$. coli was isolated from four patients, three of whom had NSV. There were also single isolations of Proteus mirabilis, Haemophilus influenzae and N. gonorrhoeae.

TABLE I

Vaginal bacterial counts in patients with different clinical conditions

\begin{tabular}{|c|c|c|c|c|c|c|c|}
\hline \multirow{2}{*}{$\begin{array}{l}\text { Patient group } \\
\qquad(\mathrm{n}=)\end{array}$} & \multicolumn{2}{|c|}{$\begin{array}{l}\text { Number of patients with } \\
\text { positive cultures for }\end{array}$} & \multicolumn{3}{|c|}{$\begin{array}{l}\text { Mean (range) bacterial } \\
\text { count }\left(\log _{10} \mathrm{cfu} / \mathrm{g}\right)\end{array}$} & \multicolumn{2}{|c|}{$\begin{array}{c}\text { Mean number of species } \\
\text { isolated }\end{array}$} \\
\hline & Aerobes & Anaerobes & Total & Aerobes & Anaerobes & Aerobic & Anaerobic \\
\hline $\begin{array}{c}\text { All subjects } \\
(102)\end{array}$ & 101 & 92 & $\begin{array}{c}8 \cdot 2 \\
(5 \cdot 5-11 \cdot 0)\end{array}$ & $\begin{array}{c}7 \cdot 2 \\
(5 \cdot 5-8 \cdot 9)\end{array}$ & $\begin{array}{c}8 \cdot 1 \\
(5 \cdot 4-11 \cdot 0)\end{array}$ & $2 \cdot 1$ & $2 \cdot 3$ \\
\hline $\begin{array}{c}\text { Gonorrhoea } \\
\text { (11) }\end{array}$ & 11 & 11 & $\begin{array}{c}8 \cdot 2 \\
(6 \cdot 6-9 \cdot 1)\end{array}$ & $\begin{array}{c}7.7 \\
(6 \cdot 4-8.9)\end{array}$ & $\begin{array}{c}8 \cdot 0 \\
(6 \cdot 2-9 \cdot 1)\end{array}$ & $2 \cdot 1$ & $1 \cdot 8$ \\
\hline $\begin{array}{c}\text { Trichomoniasis } \\
\text { (17) }\end{array}$ & 17 & 17 & $\begin{array}{c}8 \cdot 4 \\
(7 \cdot 8-9 \cdot 5)\end{array}$ & $\begin{array}{c}7.3 \\
(5 \cdot 7-8 \cdot 9)\end{array}$ & $\begin{array}{c}8 \cdot 3 \\
(7 \cdot 4-9 \cdot 5)\end{array}$ & $1 \cdot 8$ & $2 \cdot 6$ \\
\hline $\begin{array}{c}\text { Candidiasis } \\
(17)\end{array}$ & 16 & 10 & $\begin{array}{c}7 \cdot 8 \\
(5 \cdot 6-11 \cdot 0)\end{array}$ & $\begin{array}{c}7.0 \\
(4.8-8.5)\end{array}$ & $\begin{array}{c}7 \cdot 8 \\
(5 \cdot 5-11 \cdot 0)\end{array}$ & $2 \cdot 0$ & $2 \cdot 7$ \\
\hline NSV (14) & 14 & 13 & $\begin{array}{c}8 \cdot 3 \\
(5 \cdot 7-9 \cdot 7)\end{array}$ & $\begin{array}{c}7 \cdot 2 \\
(5 \cdot 5-8 \cdot 4)\end{array}$ & $\begin{array}{c}8 \cdot 2 \\
(5 \cdot 4-9 \cdot 7)\end{array}$ & $2 \cdot 1$ & $2 \cdot 5$ \\
\hline NSGI (7) & 7 & 6 & $\begin{array}{c}8 \cdot 3 \\
(5 \cdot 5-9 \cdot 0)\end{array}$ & $\begin{array}{c}7.0 \\
(5 \cdot 5-8 \cdot 0)\end{array}$ & $\begin{array}{c}8 \cdot 0 \\
(7 \cdot 2-8 \cdot 9)\end{array}$ & $2 \cdot 3$ & $2 \cdot 3$ \\
\hline $\begin{array}{c}\text { NSU contact } \\
\text { (16) }\end{array}$ & 16 & 15 & $\begin{array}{c}8 \cdot 2 \\
(7 \cdot 3-9 \cdot 0)\end{array}$ & $\begin{array}{c}7.3 \\
(4 \cdot 0-8 \cdot 9)\end{array}$ & $\begin{array}{c}7 \cdot 7 \\
(5 \cdot 7-8 \cdot 8)\end{array}$ & $2 \cdot 2$ & $2 \cdot 4$ \\
\hline $\begin{array}{r}\text { Control } \\
\text { (20) }\end{array}$ & 20 & 20 & $\begin{array}{c}8 \cdot 4 \\
(5 \cdot 7-9 \cdot 4)\end{array}$ & $\begin{array}{c}7 \cdot 4 \\
(5 \cdot 5-8 \cdot 2)\end{array}$ & $\begin{array}{c}8 \cdot 2 \\
(7 \cdot 2-9 \cdot 2)\end{array}$ & $2 \cdot 3$ & $2 \cdot 7$ \\
\hline
\end{tabular}

$\mathrm{NSV}=$ non-specific vaginitis; NSGI = non-specific genital infection; NSU = non-specific urethritis. 


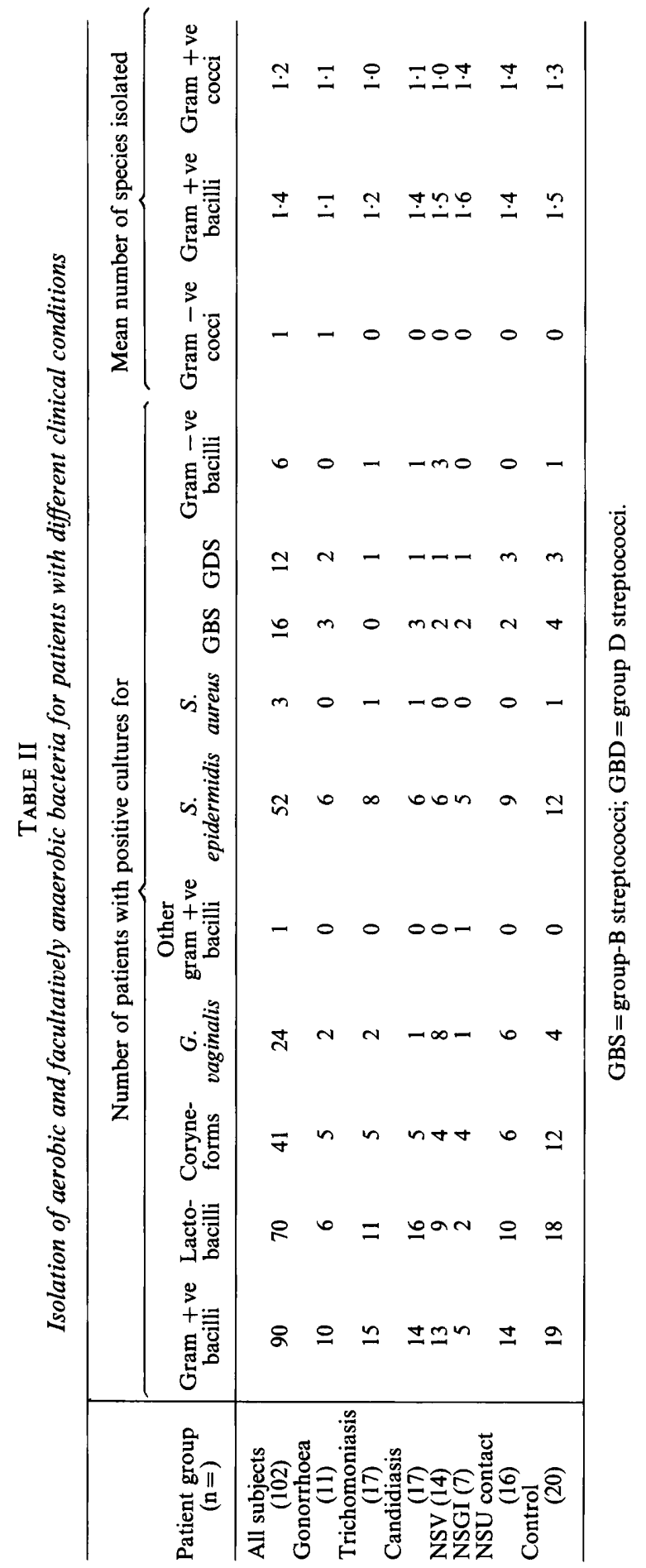




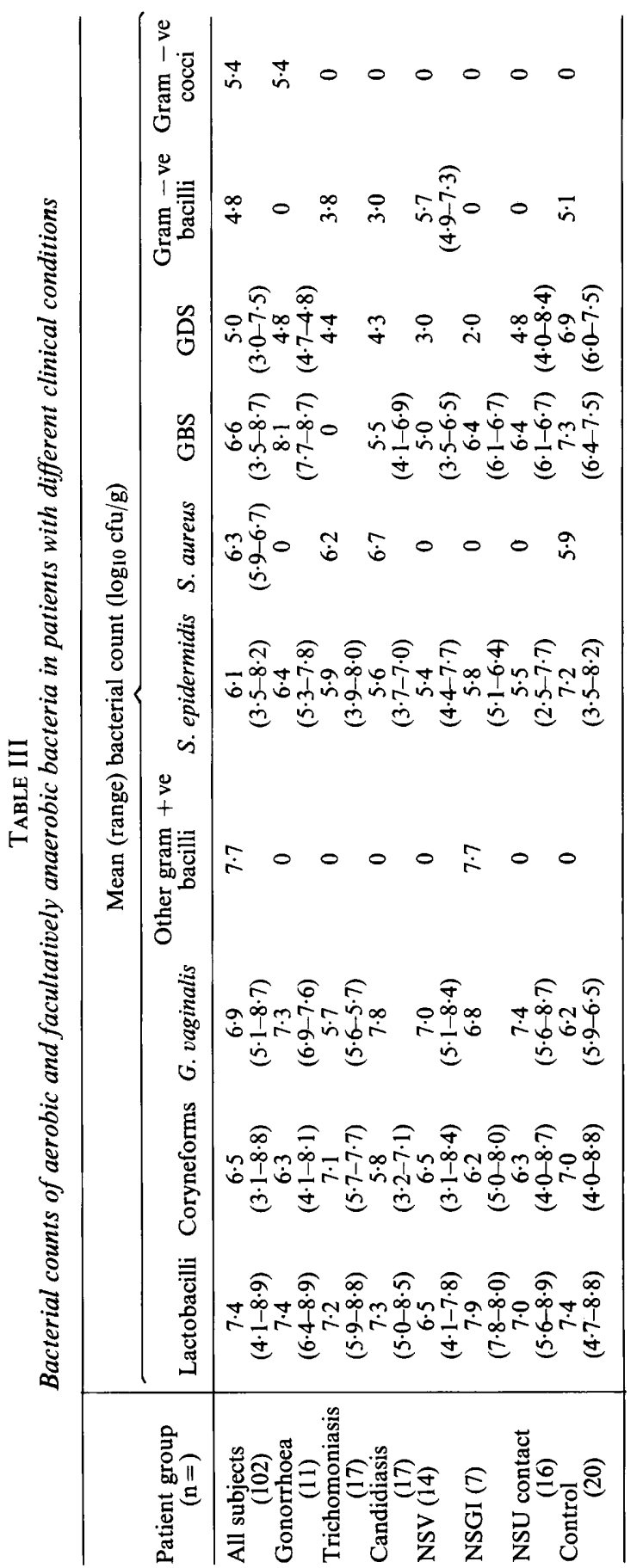




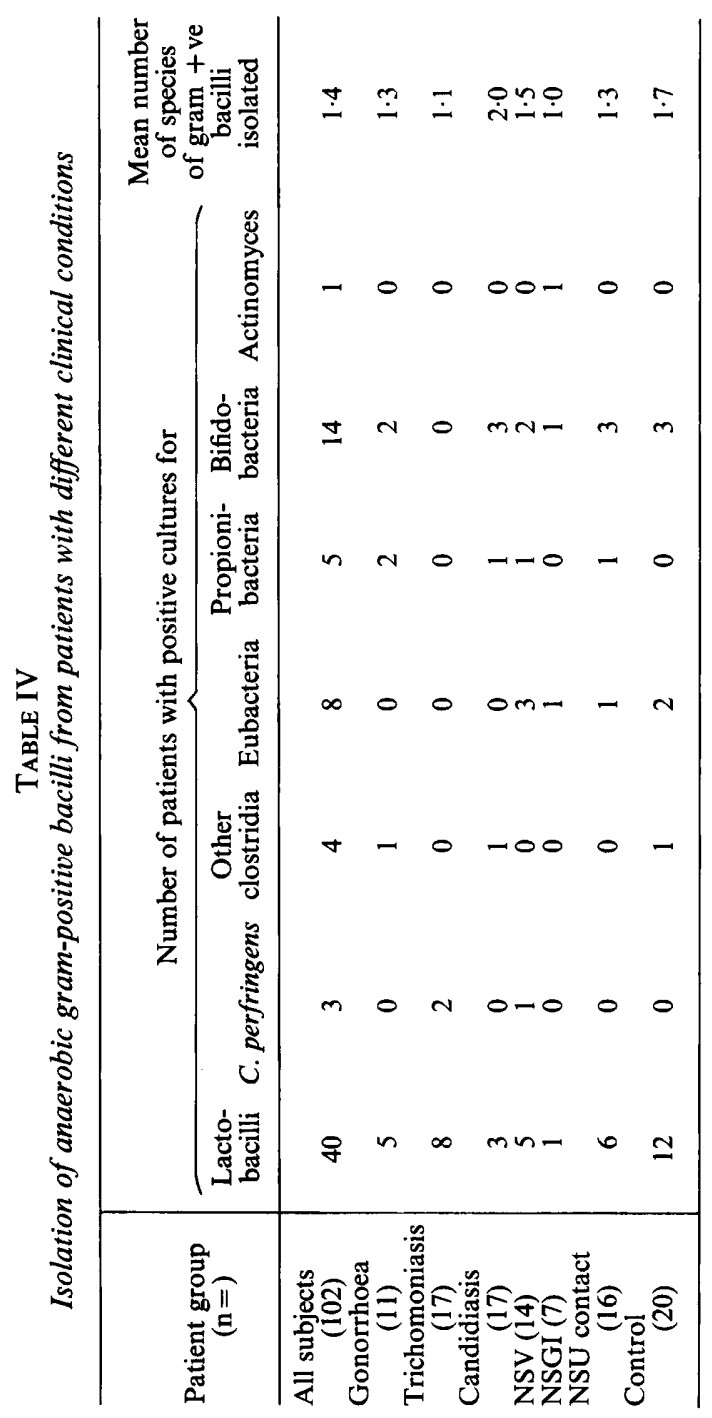




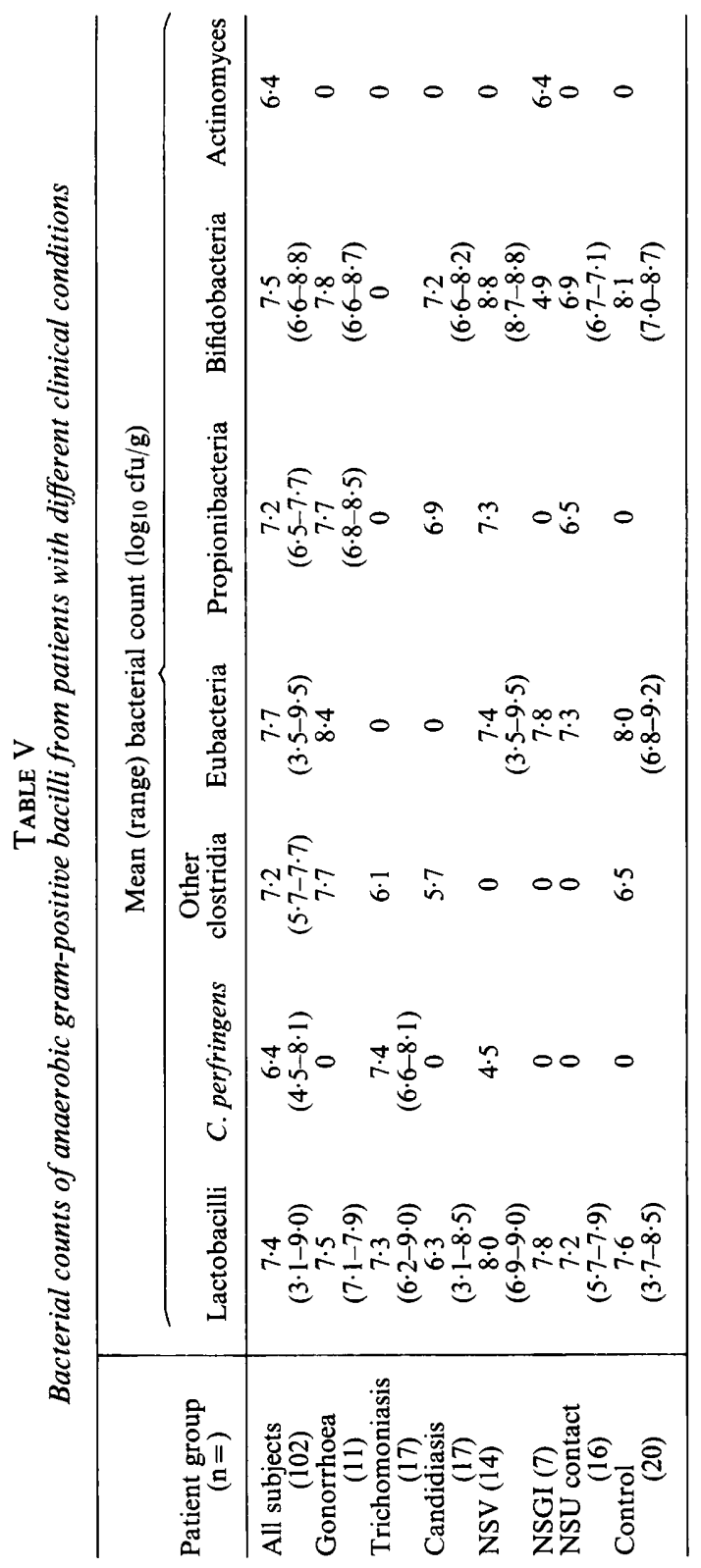




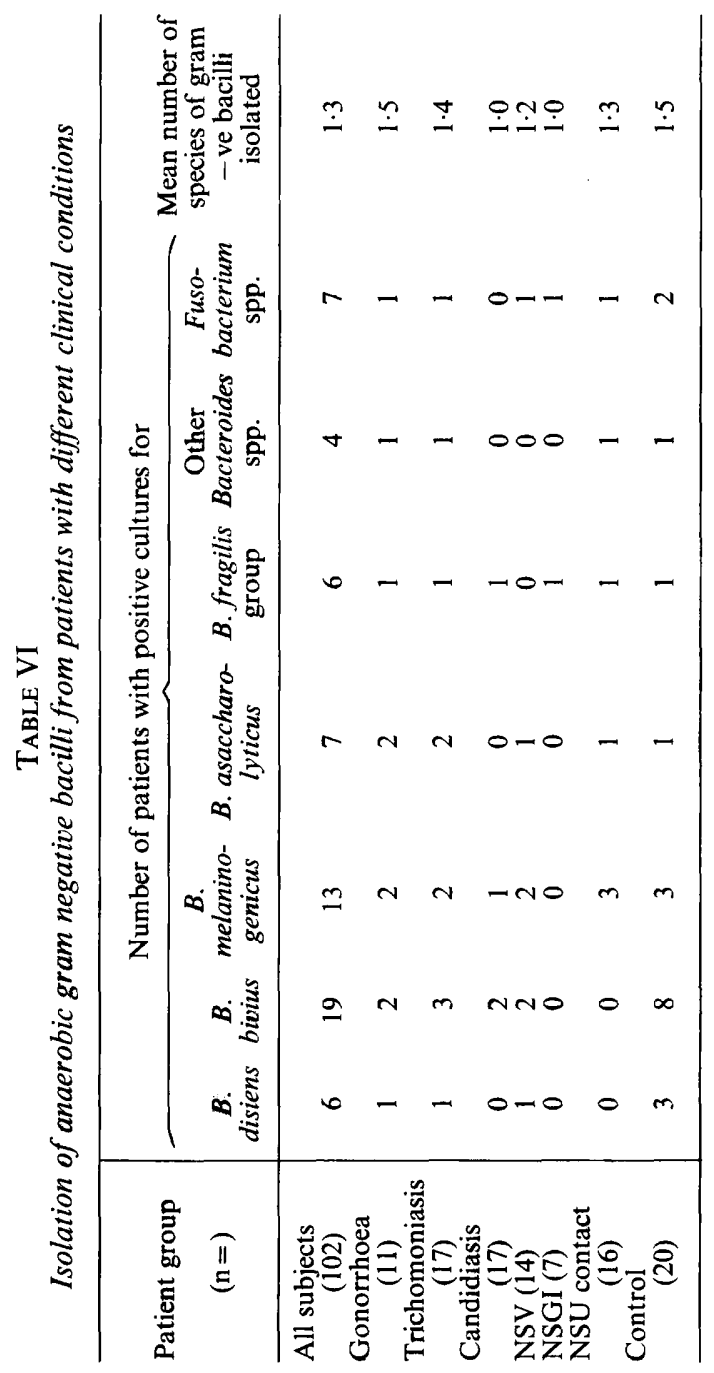




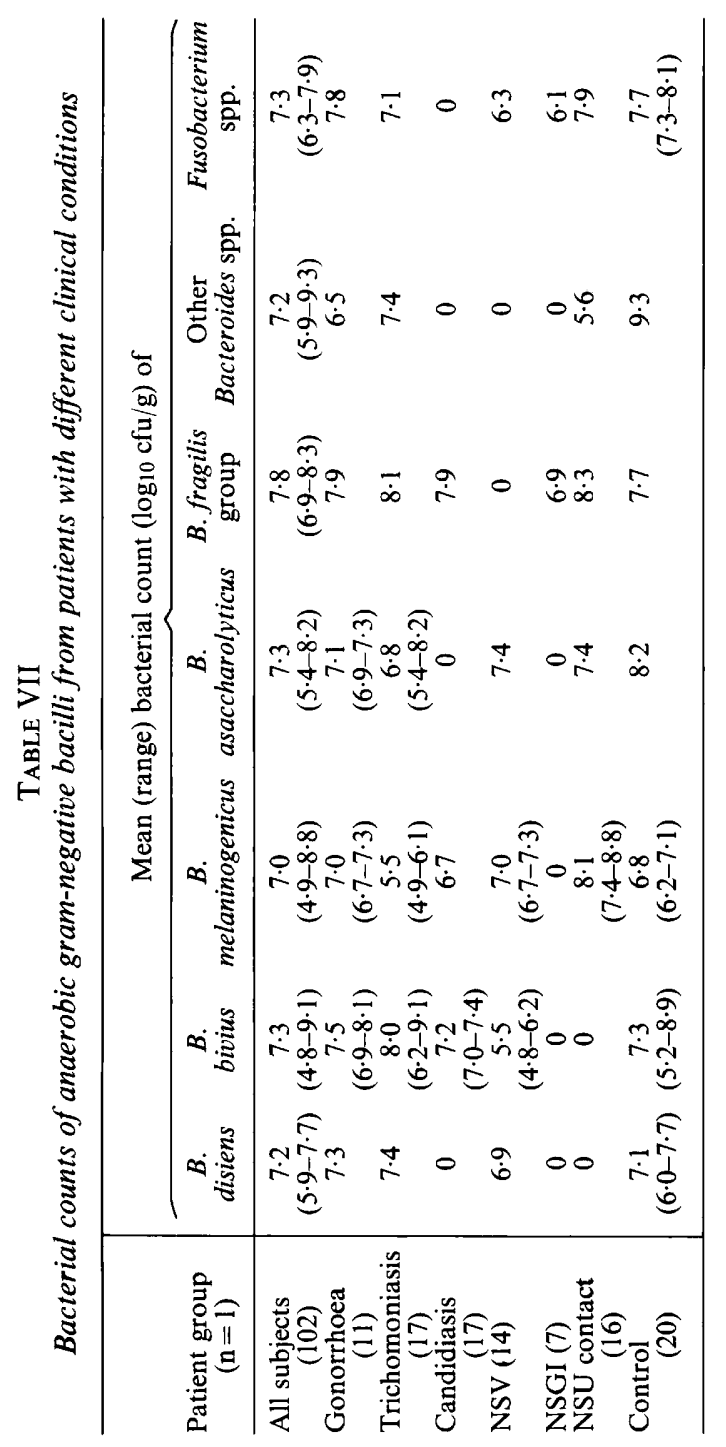




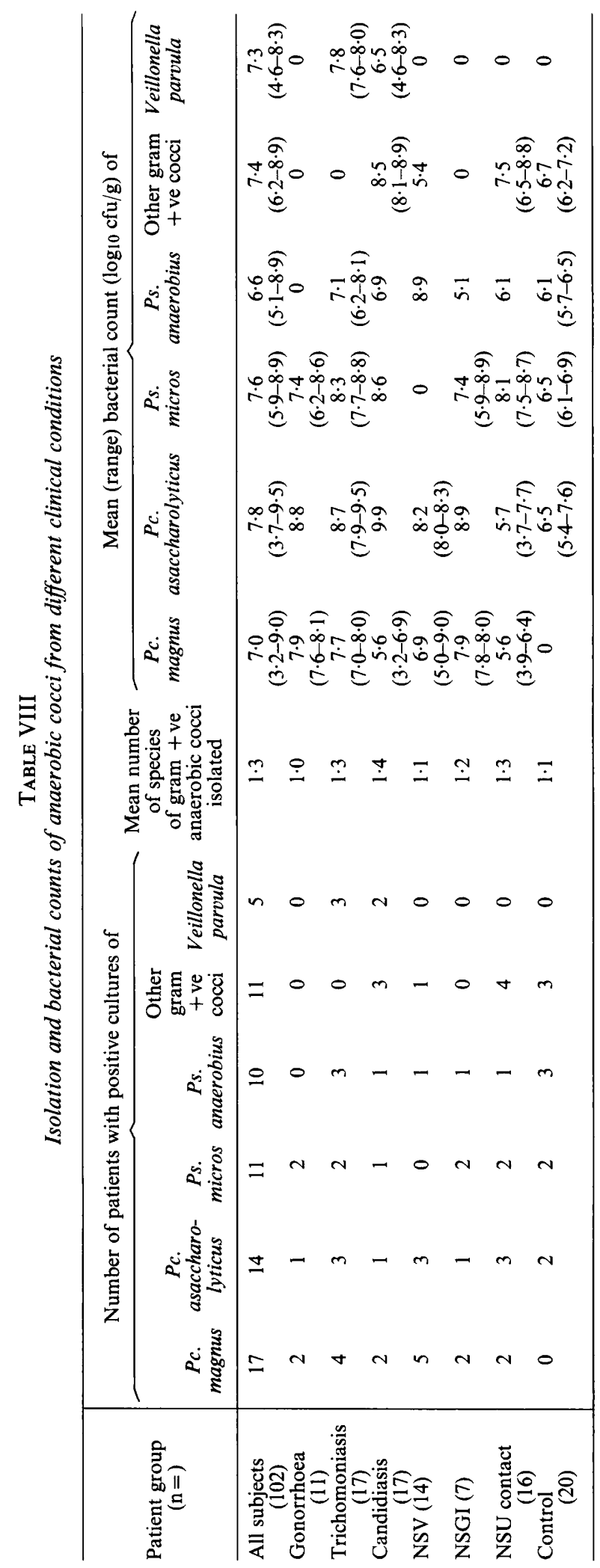


Anaerobic flora. The results of the studies of the anaerobic flora are shown in tables IV-VII. The commonest gram-positive bacilli were lactobacilli. Other gram-positive bacilli were found much less often. There was a well developed flora of gram-negative bacilli, which consisted almost entirely of Bacteroides spp; fusobacteria were isolated much less frequently. Most of the Bacteroides spp. isolated belonged to the $B$. melaninogenicus/oralis group; only six strains of the $B$. fragilis group were isolated.

The anaerobic cocci isolated are shown in table VIII. The most common species are listed separately. All gram-negative anaerobic cocci that produced acetic and propionic acids as the major fermentation products were identified as Veillonella parvula, whether they were catalase-positive or -negative (Mays et al., 1982).

\section{DisCUSSION}

Although several quantitative studies of the vaginal flora have now been published, it is apparent that the application of quantitative methods and improved anaerobic techniques has not led to the emergence of an overall consensus on the constitution of the vaginal flora in health and disease. The differences in results can be partially explained as being due to a number of different factors. First, different patient populations have been studied. In this study, patients were those attending a venereal diseases clinic and were, therefore, mainly symptomatic and self referred. Other studies have used similar patients (Taylor et al., 1982), healthy volunteers (Bartlett et al., 1977), pregnant women (Levison et al., 1977), prehysterectomy patients (Bartlett et al., 1978) or women attending a family planning clinic either for contraceptive advice or because they had vaginitis (Levison et al., 1979). Second, the criteria used in assigning patients to different diagnostic groups have been very varied. In one study of 25 "healthy patients", 18 were pregnant and six of these had gonorrhoea (Levison et al., 1977 ) and in another study, the role of anaerobic bacteria in cervicitis is discussed, but $81 \%$ of the women with cervicitis also had positive findings for $T$. vaginalis infection (Lindner et al., 1978).

In the design of such studies, patients may be sampled on a number of occasions or just once, or they may take their own samples. Different quantitative methods of sample collection can also give variable results (Wilks et al., 1982), and the addition of a diluent to collect secretions ("vaginal washings") makes the results at best semiquantitative (Spiegel et al., 1980). After the collection of samples most workers have used methods similar to those described here that involve prereduced transport media, rapid transport of specimens and, often, the use of an anaerobic chamber.

This study shows that anaerobes are present as an important and often dominant constituent of the vaginal bacterial flora in healthy women and also in a wide range of pathological conditions. The incidence of the traditional aerobic components (lactobacilli, streptococci and coagulase-negative staphylococci) was not directly affected by the presence or absence of anaerobes. Very similar results on the dominance of anaerobes in the vaginal flora were obtained by Bartlett et al. (1977) who found the mean concentrations of aerobes and anaerobes in 52 specimens from 22 healthy women to be $8 \cdot 1$ and $9 \cdot 1 \log _{10} \mathrm{cfu} / \mathrm{ml}$ of secretion. Recent qualitative studies using anaerobic techniques have also shown high isolation rates of anaerobes (Hill, 1980; Larsen and Galask, 1982). Other workers have suggested that anaerobes are 
unusual in the healthy vagina. Taylor et al. (1982) found that most normal women had lactobacilli (presumably aerobic strains) as the sole predominant organism and anaerobes were rarely present.

Ideas on the constitution of the aerobic vaginal flora have not been changed by recent studies; lactobacilli, corynebacteria, coagulase-negative staphylococci and streptococci have long been considered the most common organisms. In this study we isolated aerobic strains of lactobacilli at a mean concentration of $7 \cdot 2 \log _{10} \mathrm{cfu} / \mathrm{g}$ from $60 \%$ of all patients. We did not identify our lactobacilli isolates further because of the lack of a generally accepted identification scheme, although recently a new scheme has been proposed (Fagnant, Sanders and Sanders, 1982). Coryneforms were isolated from $40 \%$ of our patients at a mean count of $6.7 \log _{10} \mathrm{cfu} / \mathrm{g}$, although they never occurred in very high concentrations and were never the most numerous organism present in a sample. It has been proposed that they, like lactobacilli, have a protective role in the female genital tract, preventing colonisation by virulent organisms, although there is no evidence for this role (Galask et al., 1976; Larsen and Galask, 1982).

Probably the only aspect of vaginal bacterial flora on which there is complete agreement is that $S$. epidermidis is very common and $S$. aureus rare. Like the corynebacteria, $S$. epidermidis did not occur in very high concentrations and its role in the vaginal flora is not known. Bramley, Dixon and Jones (1981) found that there was an association between the presence of $G$. vaginalis and "unclassified staphylococci" and an increase in abnormal vaginal signs and symptoms, especially an offensive odour. There was no correlation in our study between the presence of $G$. vaginalis and staphylococci, coagulase-positive or -negative. The low incidence of $S$. aureus in the vagina is significant because of its role as the causative agent of toxic shock syndrome. There is some evidence suggesting that most women harbour $S$. aureus in the vagina but that colonisation is only transient (Brown, 1982). It may be introduced into the vagina from the vulva where the carriage rate of $S$. aureus was found to be $67 \%$ in a recent study (Aly, Britz and Maibach, 1979). We have obtained some qualitative evidence in support of this (Wilks, Symonds and Tabaqchali, unpublished observations).

Döderlein's concept that the vaginal flora was essentially homogeneous and consisted of lactobacilli and little else remained generally accepted until the 1970's, in spite of the isolation of anaerobes from the vagina by many workers (Burdon, 1928; Harris and Brown, 1929; Weinstein, 1938). The work of Gorbach et al. (1973) re-established the importance of anaerobes as constituents of the vaginal flora. Anaerobic lactobacilli have been found to be the commonest anaerobic gram-positive bacilli present when a suitable medium, such as Rogosa agar incubated anaerobically has been used. Other gram-positive bacilli are much less common. Clostridium perfringens has been found more often than other clostridia, as was the case in this study. Although Hafiz and co-workers isolated $C$. difficile from $18 \%$ of women attending a family planning clinic and from $72 \%$ of women attending a venereal disease clinic (Hafiz et al., 1975; Bramley et al., 1981), we isolated it only once. However, we subsequently obtained a higher isolation rate $(11 \%)$ using an enrichment medium (O'Farrell et al., 1984).

In this study, as in nearly all others, most of the gram-negative bacilli were Bacteroides spp. of the melaninogenicus/oralis group, although Bacteroides spp. 
isolated in this hospital from obstetric and gynaecological infections tend to belong to the $\boldsymbol{B}$. fragilis group. Conversely, the most common anaerobic gram-positive cocci were those of the same species that have been implicated in infections.

Although $N$. gonorrhoeae was isolated only once by our quantitative technique, this is not surprising because we sampled the posterior fornix, which is known to be a sub-optimal site for the isolation of gonococci. Patients in this group had positive results for $N$. gonorrhoeae from urethral, cervical or rectal sites. The presence of the three traditional pathogens, $N$. gonorrhoeae, $T$. vaginalis and $C$. albicans did not greatly affect the vaginal flora when compared with the control group in our study. Other workers have found an increased incidence of anaerobes in trichomoniasis (Goldacre et al., 1979). We found a combination of $G$. vaginalis and anaerobic gram-positive cocci in seven out of 14 patients with NSV and in five out of 16 NSU contact patients. We have discussed the significance of this combination in the pathogenesis of NSV in detail elsewhere (Tabaqchali, Wilks and Thin, 1983). A similar association between the presence of $G$. vaginalis and anaerobes was found by Spiegel et al. (1980) and Taylor et al. (1982). However, Balsdon et al. (1980) isolated anaerobic cocci from one of 30 patients with non specific vaginitis, all of whom gave positive cultures for $G$. vaginalis.

It is clear that no overall consensus has emerged on the occurrence and significance of the anaerobic vaginal flora. It has been suggested that anaerobes have a protective role, preventing the overgrowth by potential pathogens as in the gastrointestinal tract (Larsen and Galask, 1982). In contrast, other workers have suggested that the presence of anaerobes themselves is of pathogenic significance, either causing disease or associated with it. From our work, we conclude that although certain anaerobes such as the gram-positive cocci may have a role in the pathogenesis of NSV, the mere presence of anaerobes cannot be regarded as being of pathogenic significance. It is unlikely that further studies based on the analysis of single samples will clarify the situation further. The use of repeated sampling techniques to study fluctuations in the vaginal flora in vivo and the use of mixed continuous culture techniques in vitro may provide a better understanding of the significance of the vaginal flora.

This work was supported by the Joint Research Board of St Bartholomew's Hospital. We thank Sister and the nursing staff of the Department of Genital Medicine for their help in collecting specimens and Miss Lorraine Hall for typing the manuscript.

\section{REFERENCES}

Aly R, Britz M B, Maibach H I 1979 Quantitative microbiology of human vulva. British Journal of Dermatology 101:445-448.

Balsdon M J, Taylor G E, Pead L, Maskell R 1980 Corynebacterium vaginale and vaginitis: a controlled trial of treatment. Lancet 1:501-504.

Bartlett J G, Onderdonk A B, Drude E, Goldstein C, Anderka M, Alpert S, McCormack W M 1977 Quantitative bacteriology of the vaginal flora. Journal of Infectious Diseases 136:271-277.

Bartlett J G, Moon N E, Goldstein P R, Goren B, Onderdonk A B, Polk B F 1978 Cervical and vaginal bacterial flora: Ecologic niches in the female lower genital tract. American Journal of Obstetrics and Gynecology 130:658-661.

Bramley H M, Dixon R A, Jones B M 1981 Haemophilus vaginalis (Corynebacterium vaginale, Gardnerella vaginalis) in a family planning clinic population. British Journal of Venereal Diseases 57:62-66. 
Brown W J 1982 Variations in the vaginal bacterial flora: a preliminary report. Annals of Internal Medicine 96:931-934.

Burdon K L 1928 Bacterium melaninogenicum from normal and pathologic tissues. Journal of Infectious Diseases 42:161-171.

Clarke T J 1977 Methods for studying gut microbes. In: Clarke R T J, Bauchop T (eds) The microbial ecology of the gut, Academic Press, London, pp. 1-33.

Collins M D, Jones D 1981 Distribution of isoprenoid quinone structural types in bacteria and their taxonomic implications. Microbiological Reviews 45:316-354.

Cowan S T 1974 Cowan and Steele's Manual for the identification of medical bacteria, 2 nd ed. Cambridge University Press, Cambridge.

Curtis A H 1913 A mobile curved anaerobic bacillus in uterine discharges. Journal of Infectious Diseases 12:165-169.

Fagnant J E, Sanders C C, Sanders W E 1982 Development and evaluation of a biochemical scheme for identification of endocervical lactobacilli. Journal of Clinical Microbiology 16:926-934.

Galask R P, Larsen B, Ohm M J 1976 Vaginal flora and its role in disease entities. Clinical Obstetrics and Gynaecology 19:61-81.

Goldacre M J, Watt B, Loudon N, Milne L J R, Loudon J D O, Vessey M P 1979 Vaginal microbial flora in normal young women. British Medical Journal 1:1450-1453.

Gorbach S L, Menda K B, Thadepalli H, Keith L 1973 Anaerobic microflora of the cervix of healthy women. American Journal of Obstetrics and Gynecology 117:1053-1055.

Hafiz S, McEntegart M G, Morton R S, Waitkins S A 1975 Clostridium difficile in the urogenital tract of males and females. Lancet 1:420-421.

Harris J W, Brown J H 1929 A clinical and bacteriological study of 113 cases of streptococcic puerperal infection. Bulletin of the Johns Hopkins Hospital 44:1-31.

Hill G B 1980 Anaerobic flora of the female genital tract. In: Lambe D W, Genco R J, Mayberry Carson K J (eds) Anaerobic bacteria, selected topics. Plenum Press, New York pp 39-50.

Holdeman L V, Cato E P, Moore W E C 1977 Anaerobe Laboratory Manual, 4th edn. Virginia Polytechnic Institute and State University, Blacksburg, Virginia.

Hungate R E 1950 The anaerobic mesophilic cellulolytic bacteria. Bacteriological Reviews $14: 1-49$.

Larsen B, Galask R P 1982 Vaginal microbial flora: composition and influence of host physiology. Annals of Internal Medicine 96:926-930.

Levison M E, Corman L C, Carrington E R, Kay C D 1977 Quantitative microflora of the vagina. American Journal of Obstetrics and Gynecology 127:80-85.

Levison M E, Trestman I, Quach R, Sladowski C, Flora C N 1979 Quantitative bacteriology of the vaginal flora in vaginitis. American Journal of Obstetrics and Gynecology 133:139-144.

Lindner J G E M, Plantema F H F, Hoogkamp-Korstanje J A A 1978 Quantitative studies of the vaginal flora of healthy women and of obstetric and gynaecological patients. Journal of Medical Microbiology 11:233-241.

Mays T D, Holdeman L V, Moore W E C, Rogosa M, Johnson J L 1982 Taxonomy of the Genus Veillonella Prevot. International Journal of Systematic Bacteriology 32:28-36.

O'Farrell S, Wilks M, Nash J Q, Tabaqchali S 1984 A selective enrichment broth for the isolation of Clostridium difficile. Journal of Clinical Pathology 37:98-99.

Onderdonk A B, Polk B F, Moon N E, Goren B, Bartlett J G 1977 Methods for quantitative vaginal flora studies. American Journal of Obstetrics and Gynecology 128:777-781.

Piot P, van Dyck E, Totten P A, Holmes K K 1982 Identification of Gardnerella (Hemophilus) vaginalis. Journal of Clinical Microbiology 15:19-24.

Riddell R H, Buck A C 1970 Trimethoprim as an additional selective agent in media for the isolation of $N$. gonorrhoeae. Journal of Clinical Pathology 23:481-483.

Spiegel C A, Amsel R, Eschenbach D, Schoenknecht F, Holmes K K 1980 Anaerobic bacteria in non-specific vaginitis. New England Journal of Medicine 303:601-607.

Sutter V L, Vargo V L, Finegold S M 1975 Wadsworth anaerobic bacteriology manual, 2nd edn. University Extension and School of Medicine UCLA, Los Angeles, CA.

Tabaqchali S 1970 The pathophysiological role of small intestinal bacterial flora. Scandinavian Journal of Gastroenterology 5, Suppl 6: 139-163. 
Tabaqchali S, Wilks M, Thin R N 1983 Gardnerella vaginalis and anaerobic bacteria in genital disease. British Journal of Venereal Disease 59:111-115.

Taylor E, Blackwell A L, Barlow D, Phillips I 1982 Gardnerella vaginalis, anaerobes and vaginal discharge. Lancet 1:1376-1379.

Weinstein L 1938 The bacterial flora of the human vagina. Yale Journal of Biological Medicine $10: 247-260$.

Wilks M, Thin R N, Tabaqchali S 1982 Quantitative methods for studies on vaginal flora. Journal of Medical Microbiology 15:141-147. 